Primack, B. A., Colditz, J. B., Rosen, E. B., Giles, L. M., Jackson, K. M., \& Kraemer, K. L. (2017). Portrayal of alcohol brands popular among underage youth on YouTube: A content analysis. Journal of Studies on Alcohol and Drugs, 78(5), 654-664. https://doi.org/10.15288/jsad.2017.78.654

\title{
Portrayal of Alcohol Brands Popular among Underage Youth on YouTube: A Content Analysis
}

\author{
Brian A. Primack, M.D., Ph.D., ${ }^{\text {a,b,c }}$ \\ Jason B. Colditz, M.Ed. ${ }^{\text {a,b }}$ \\ Eva Rosen ${ }^{\mathrm{a}, \mathrm{d}}$ \\ Leila M. Giles, B.S., ${ }^{\text {ab }}$ \\ Kristina Jackson, Ph.D. ${ }^{e}$ \\ Kevin L. Kraemer, M.D., M.Sc. ${ }^{b}$
}

${ }^{a}$ Center for Research on Media, Technology, and Health, University of Pittsburgh, 230 McKee Place Suite 600, Pittsburgh, PA 15213

${ }^{\mathrm{b}}$ Division of General Internal Medicine, Department of Medicine, University of Pittsburgh School of Medicine, 933W Montefiore Hospital, Pittsburgh, PA 15213

${ }^{c}$ Division of Adolescent Medicine, Department of Pediatrics, University of Pittsburgh School of Medicine, 3420 Fifth Avenue, Pittsburgh, PA 15213

${ }^{\mathrm{d}}$ University of Michigan, Ann Arbor, MI 48109

${ }^{\mathrm{e}}$ Center for Alcohol and Addiction Studies, Department of Behavioral and Social Sciences Brown School of Public Health, Brown University, 121 South Main Street, Providence, RI 02912

*Corresponding Author:

Brian A. Primack, MD, PhD

230 McKee Place Suite 600

Pittsburgh, PA 15213

bprimack@pitt.edu; 412-586-9789 (phone); 412-692-4838 (fax)

Research support: ABMRF, The Foundation for Alcohol Research

Short Title: Alcohol Brands on YouTube

Words in abstract: 250

Words in text: 3984

Tables: 3

Figures: 0 


\begin{abstract}
Objective. We characterized leading YouTube videos featuring alcohol brand references and examined video characteristics associated with each brand and video category.
\end{abstract}

Method. We systematically captured the 137 most relevant and popular videos on YouTube portraying alcohol brands that are popular among underage youth. We employed an iterative process to codebook development. We coded variables within domains of video type, character socio-demographics, production quality, and negative and positive associations with alcohol use. All variables were double coded, and Cohen's $\kappa>0.80$ for all variables except age, which was eliminated.

Results. There were 96,860,936 combined views for all videos. The most common video type was "traditional advertisements," which comprised $40 \%$ of videos. Of the videos, $20 \%$ were "guides" and 10\% focused on chugging a bottle of hard liquor. While $95 \%$ of videos featured males, $40 \%$ featured females. Alcohol intoxication was present in $19 \%$ of videos. Aggression, addiction, and injuries were uncommonly identified (2\%, 3\%, and 4\%, respectively), but $47 \%$ of videos contained humor. Traditional advertisements represented the majority of videos related to Bud Light (83\%) but only $18 \%$ of Grey Goose and $8 \%$ of Hennessy videos. Intoxication was most present in chugging demonstrations (77\%), while addiction was only portrayed in music videos $(22 \%)$. Videos containing humor ranged from $11 \%$ for music-related videos to $77 \%$ for traditional advertisements. 
Conclusions. YouTube videos depicting the alcohol brands favored by underage youth are heavily viewed, and the majority are traditional or narrative advertisements. Understanding characteristics associated with different brands and video categories may aid in intervention development.

Keywords. Alcohol, Intoxication, Social media, YouTube, Qualitative methods 


\section{INTRODUCTION}

Early initiation of alcohol consumption is associated with negative consequences such as other drug use, automobile accidents, development of chronic alcohol use disorders, violence, early sexual activity, and is the leading cause of premature death among adolescents and young adults (Connery et al., 2014; Hingson et al., 2002; Marshall, 2014; World Health Organization, 2016). Despite our understanding of the impact of alcohol use on adolescents, consumption remains high: U.S. nationally representative data indicate that $34.9 \%$ are current drinkers, defined as having a complete alcoholic drink during the past 30 days, and $20.8 \%$ of adolescents have consumed 5 alcoholic beverages within a couple of hours at least once in the past 30 days (Centers for Disease Control and Prevention, 2016).

Many socio-demographic, personal, and environmental factors are linked to alcohol use in adolescence and young adulthood (Marshall, 2014; McCambridge et al., 2011; Patrick \& Schulenberg, 2013). However, exposures to alcohol in media messages are emerging as particularly important factors (Anderson et al., 2008; Hanewinkel et al., 2014; McClure et al., 2016; Roberts et al., 2015). For example, youth are exposed to about 2-4 alcohol advertisements daily via various media outlets, including television and online sources (Collins et al., 2016) and about 35 references to explicit alcohol use daily in popular music, and the vast majority of these messages associate alcohol use with social, sexual, and financial success (Primack et al., 2008, 2012). 
Exposures to both narrative (e.g., movies and TV shows) and persuasive (e.g., advertisements and merchandising) media messages involving alcohol are associated with negative outcomes (Anderson et al., 2008; Engels et al., 2009; Grenard et al., 2013; McClure et al., 2009; Tanski et al., 2015). For example, watching popular music videos that contain content relating to alcohol use has been independently associated with earlier drinking onset, increased consumption, and decreases in the perceived risks of drunk driving (Beullens \& Van den Bulck, 2008; Robinson et al., 1998; van den Bulck \& Beullens, 2005). Additionally, exposure to brand-specific advertisements is associated with increased consumption of popular brands (Ross et al., 2014), and that association has been found to be a dose-response relationship (Barry, 2016).

The combination of alcohol ad exposure and a positive affective reaction to those ads appears to influence some youth to subsequently drink and experience drinking-related problems to a greater extent (Grenard et al., 2013). Further, youth exposed peers' video content related to drinking and alcohol brands may develop more favorable norms and expectancies related to drinking, and ultimately more alcohol use. Indeed, the associations between alcohol marketing and underage binge drinking has been found to be mediated by variables related to norms for peers being drunk, alcohol expectancies, having a favorite brand, and drinker identity (McClure et al., 2013).

Some of the fastest growing media exposures are Internet-based (Barry, Bates, et al., 2015; McClure et al., 2016). This is an important area for research because Internet access is widely available to youth, with $92 \%$ of teens reporting daily use (Lenhart, 2015). News reports indicate that alcohol industry digital media marketing spending has grown rapidly, but since it is much 
less expensive, the full impact of this growth is not shown in percent of marketing budget spent on digital enterprises alone (Jernigan \& Rushman, 2014). Per capita exposure to alcoholcontaining YouTube music videos is nearly four times higher in adolescents (Cranwell et al., 2016).

While many studies have investigated the effect of alcohol advertisements on Facebook, Twitter, and Instagram, little research has been done on video sharing platforms such as YouTube (Moreno \& Whitehill, 2014). Video sharing platforms can combine the compelling high production values of traditional visual media with influential peer-to-peer dialogue (Huang et al., 2016; Oksanen et al., 2015). A 2014 study found that, of children who use the Internet, at least once during the previous month $85 \%$ had watched online video clips, compared to $76 \%$ for using the Internet for schoolwork and $71 \%$ visiting a social networking profile (Mascheroni \& Ólafsson, 2014). YouTube is currently the most popular video sharing site, with over 1 billion unique users monthly. Furthermore, the frequency at which people access YouTube daily on the Internet has increased $40 \%$ per year for the past several years, and viewing videos on mobile devices recently increased year over year by 100\% (YouTube, 2016).

Prior research has examined representations of alcohol intoxication on YouTube. This research helped elucidate the volume of exposure; for example, 70 systematically-obtained videos related to alcohol intoxication had been viewed about a third of a billion times (Primack et al., 2015). This research also found that humor was juxtaposed with alcohol use in $79 \%$ of videos and motor vehicle use was present in $24 \%$ of videos (Primack et al., 2015). Another study found that $44 \%$ of videos involved some type of alcohol brand appearance (ABA) (Primack et al., 2015). ABAs 
are important to assess because they may function as advertising, whether or not they are paid for or sanctioned by the alcohol industry (Primack et al., 2014). Furthermore, developing brand recognition is a crucial step in the marketing of any product, and companies attempt to create positive associations with their brands through product placement activities (Barry, 2016; Cranwell et al., 2015). Moreover, brand recognition and having a favorite brand are independent, potent risk factors for the initiation and maintenance of the use of these substances among adolescents (Henriksen et al., 2008; Volk et al., 1996).

Our first aim was to systematically obtain a set of YouTube videos that include ABAs for brands popular among youth. We focused on youth-oriented brands because of the value in intervening with this demographic. Second, we aimed to characterize the content of these ABA-containing videos. Finally, we aimed to determine what video characteristics were associated with each specific brand and each video type (e.g., advertisement vs. music video). 


\section{METHODS}

\section{Search Algorithm and Quality Control}

Based on previous research demonstrating brands of alcohol reported as favored and popular among underage drinkers (Siegel, DeJong, et al., 2013; Tanski et al., 2011), as well as those appearing in popular music (Siegel, Johnson, et al., 2013), we chose 8 search strings reflecting a variety of brands across several types of alcoholic beverages. The brands were "Bud Light" (beer), "Coors Light” (beer), "Grey Goose” (vodka), "Hennessey” (cognac), “Jack Daniel's" (whiskey), “Mike’s Hard” Lemonade (flavored alcohol drink), "Patron” (tequila), and "Smirnoff" (flavored alcohol and also vodka). We attempted to optimize each search term so as to improve sensitivity and specificity. For example, when we experimented with using "Jack Daniel" instead of "Jack Daniel's," there were a large number of false positive results based on the name "Daniel."

Video data were collected via the YouTube Application Programming Interface (API) on September 19, 2013 and analyses were conducted through mid-2014. Our sample included all videos in the first 20 hits for each search, consistent with other studies in the area (Carroll et al., 2013; Gordon et al., 2001; Leighton \& Srivastava, 1999; Madan et al., 2003; Primack et al., 2015). For each key term, we used this strategy under two separate conditions: (1) sorting videos by search term "relevance" according to YouTube's internal algorithm, and (2) sorting by "view count" in order to capture the most popular videos for each term. This was done in order to assess both content that is most commonly viewed as well as content that is most likely to come 
up in searches by youth (Carroll et al., 2013; Primack et al., 2015). This resulted in an initial pool of 320 videos ( 8 terms x 20 hits x 2 methods of sorting). There was little overlap in the video lists returned by the view count and relevance methods of sorting.

We then eliminated duplicate videos, defined as those in which more than half of the content or footage was identical $(n=81 ; 25 \%)$. We also eliminated irrelevant videos $(n=102 ; 32 \%)$, which we defined as those that did not contain any references to any type of alcohol brand. Videos in which English was not the primary language (i.e., more than half of the dialogue was in a nonEnglish language) were excluded. After eliminating extraneous videos, there remained 137 videos to analyze for alcohol-related content. We expected this number of videos to be sufficient for content analysis based on prior similar work in this area (Carroll et al., 2013; Primack et al., 2015).

To ensure data integrity and facilitate analysis, we carefully retained appropriate video identification numbers and links as they were represented on the day of the search, as in Primack et al. (2015).

\section{Codebook Development}

Codebook development followed general procedures established by Crabtree and Miller in their adaptation of qualitative research methods for health-oriented research (Crabtree \& Miller, 1999). Three researchers with qualitative research experience independently examined 10 pilot videos and performed "in vivo" coding, which involved development of descriptive codes based 
solely on the audio-visual material. Coders then met to discuss and compare their codes, adding, deleting, and collapsing codes together as necessary. Coders then coded a second series of 10 pilot videos with the new tentative codebook and met again to combine codes. This iterative process continued for 4 iterations until a final codebook was determined. In order to preserve the integrity of the final dataset, pilot training videos were not part of the final sample.

This grounded theory approach was subsequently supplemented by existing theory-based information. It was appropriate to begin with grounded theory, which involves developing codes purely based on the data, in order to fully capture the richness of the data (Strauss \& Corbin, 2007). We also felt it was important to add codes based work on content analyses related to media exposures and substance use (Forsyth \& Malone, 2010; Gruber et al., 2005; Kim et al., 2010; Primack et al., 2012). For example, prior research based on Social Cognitive Theory (Bandura, 2001) suggests that uptake of risky behaviors is increased when viewers are exposed to messages which juxtapose those behaviors with positive characteristics, such as humor and attractiveness (Bandura, 2001; Fischer et al., 2011). Therefore, while the initial codebook did not contain explicit assessment of humor and attractiveness, these variables were added for conceptual reasons. Similarly, we added variables describing alcohol-related behaviors known to be associated with substantial morbidity and mortality such as active intoxication, injury, and dependence.

To finalize the codebook, all codes were operationally defined for clarity, conciseness, and relevance to the videos. Specific examples of each code were provided to improve reproducibility and clarity. The final codebook is available from the authors. 


\section{Coding Procedures}

We followed general coding procedures outlined in prior similar research (Carroll et al., 2013; Forsyth \& Malone, 2010; Primack et al., 2015). Two trained coders worked independently to review and code the entire sample of videos. Training consisted of an ordered sequence of activities including didactic components and practice coding on other videos. While other content analyses only include double-coding for a small proportion of texts (Crabtree \& Miller, 1999), we opted to double-code all videos because this was feasible and because it improved the ultimate value of the data. For the variables coded, we computed inter-rater reliability, expressed in terms of Cohen's $\kappa$ (Cohen, 1960). While nearly all coefficients were in the excellent range $(\kappa>0.80)$ in the final coding, coders' impression of the age of participants was not reliable. Therefore, this variable was omitted from analyses. For all other variables, coders and the principal investigator worked together to achieve consensus for the few disagreements that remained.

\section{Measures}

Our final codebook contained 19 codes that broadly represented 5 categories: video type, production quality, character socio-demographics, negative associations with alcohol use, and positive associations with alcohol use (Table 1). 
Video Type. Six mutually exclusive categories represented: "music," "guides," "traditional advertisement," "narrative advertisement," "chugging," and "other". During the iterative code development process, the explicit decision was made for this category to be a mutually exclusive categorical variable instead of multiple dichotomous variables. This was done because the data naturally fell into mutually exclusive categories with very little overlap.

Production Quality. Production quality was assessed as poor, moderate, or professional. This was deemed as an important variable to capture because it was noted during the grounded theory process and the perception of the "professional" nature of a video can add to its influence.

Character Socio-Demographics. This category included 5 dichotomous variables which captured sex and race/ethnicity. Coders focused on "primary individuals," defined as those individuals pictured in an active role in the video, such as speaking, performing music, or interacting directly with a speaker or performer. Binary variables enabled coders to describe pictured individuals as male, female, White, Black, and because there were so few characters that could be clearly identified as Hispanic or Latino, Asian or Pacific Islander, and Native American, these categories were combined into "Other race/ethnicity."

Categories were not mutually exclusive, because a video might picture both females and males and individuals of multiple racial and/or ethnic groups.

Negative Associations with Alcohol Use. This category contained 5 dichotomous codes: aggression, addiction or dependence, active intoxication, injury, and motor vehicle use. 
Positive Associations with Alcohol Use. Two dichotomous codes indicated whether alcohol was associated with positive characteristics including humor and physical attractiveness. Because these factors can be subjective, these were defined as likely to be humorous or attractive to the typical adolescent viewer, the intended audience of the video.

\section{Analysis}

Because the purpose of this study was a content analysis, our analyses focused on quantitative descriptive data and qualitative, representative examples of each of the codes. We first assessed each of the video characteristics according to the specific brand of the video's focus. We also examined coded video characteristics for each of the video types (e.g., traditional advertisement, narrative advertisement, guide). Because all variables were categorical or dichotomous, we used chi-square tests, $\alpha=0.05$ (two-tailed) to define statistical significance. Tests were conducted using Stata 13.0 (Statacorp, College Station, TX). 


\section{RESULTS}

\section{Sample}

The 137 videos lasted a median of 129 (interquartile range [IQR]=61-258) seconds. Each video had been viewed a median of $116,650(\mathrm{IQR}=12,377-384,973)$ times, for a total of $96,860,936$ views for all videos combined. Included videos were published to YouTube between February 4, 2006 and September 10, 2013. The number of days a video had been online prior to data collection view count was associated with view count $(r=.31)$ and "dislikes" $(r=.21)$ but not "likes" ( $r=.04)$. The videos had a median of 302 (IQR=44-1027) "like" designations and 11 ( $\mathrm{QQR}=2-81)$ "dislike" designations each.

\section{Code Frequencies}

The most common video type was "traditional advertisements," which comprised $40 \%(\mathrm{n}=55)$ of videos. "Narrative advertisements" comprised 12\% (n=16) of the sample. One-fifth (20\%) of videos were classified as "guides" $(\mathrm{n}=27)$, and $13 \%(\mathrm{n}=18)$ were classified as primarily musicrelated. Ten percent $(\mathrm{n}=14)$ of videos were "chugging" demonstration videos, and only 7 videos did not fall into any of these categories.

The majority of videos $(61 \%, \mathrm{n}=84)$ were classified as professional in terms of production quality. About one-fourth $(26 \%, \mathrm{n}=36)$ were classified as poor, and the remaining $12 \%(\mathrm{n}=17)$ were classified as moderate. 
While $95 \%(n=130)$ of videos featured males, only $40 \%(n=55)$ featured females. Further,77\% of videos $(\mathrm{n}=106)$ depicted White individuals, 34\% $(\mathrm{n}=46)$ displayed Black individuals, and 12\% $(n=16)$ displayed individuals with other racial/ethnic categories (e.g., Hispanic and Asian).

While alcohol intoxication was apparent in 19\% $(n=26)$ of videos, addiction was only coded in $3 \%(n=4)$ of videos. Aggression and injuries were uncommonly identified (2\% and 4\%, respectively). Motor vehicle use was coded in $8 \%(n=11)$ of videos.

Nearly half $(47 \%, n=65)$ of videos contained humor, and $31 \%(n=42)$ were classified as including attractive primary characters.

\section{Associations between Video Characteristics and Brands}

There were significant differences in the category of video according to each specific brand referenced ( $p<.001$, Table 2). For example, $83 \%$ of videos related to Bud Light were traditional advertisements, but only $18 \%$ of Grey Goose videos, $8 \%$ of Hennessy videos, and none of the Patron videos were traditional advertisements.

Production quality was also significantly associated with brand $(p<.01)$. For example, more Bud Light videos were in the high production category compared with Jack Daniel's (87\% vs. 44\%). 
White and Black race were significantly associated with brand. However, there were no differences with regard to gender and other race/ethnicity.

We found significant associations between each of the negative alcohol characteristics and brand. For example, all Patron videos but none of the Bud Light videos portrayed intoxication. Intoxication among other brands ranged from $10 \%$ to $38 \%$ of videos. Only Grey Goose and Jack Daniel's videos were coded as referring to addiction or dependence (5\% and 17\%, respectively). Only Grey Goose videos portrayed aggressive behaviors, and only Bud Light videos were coded as containing injuries. Finally, proportion of videos with vehicle use ranged from $0 \%$ for Bud Light and Jack Daniel's to 44\% for Smirnoff.

For positive associations, the majority of Bud Light and Coors Light videos featured humor (87\% and $82 \%)$, while brands such as Grey Goose and Jack Daniel's were less likely to contain humor (14\% and 17\%). There was no significant association between portrayal of attractiveness and specific brand mentioned.

\section{Associations between Video Characteristics and Video Types}

Significant associations exist between negative alcohol characteristics and video categories

(Table 3). For example, intoxication was most present in chugging demonstrations (77\%), while addiction was only portrayed in music related videos (22\%). Similarly, aggression and vehicle use were the most likely to appear in videos categorized for music (11\% and 39\%). There was no significant association between the presence of injury and video category. 
We identified significant associations between both of the positive alcohol characteristics and videos categories. Videos containing humor ranged from $11 \%$ for music related videos to $77 \%$ for traditional advertisements (Table 3). Finally, attractiveness was most prevalent in narrative advertisements (62\%). 


\section{DISCUSSION}

It is noteworthy that videos such as these have been viewed so many times. One implication of this is that this medium provides an alternative for companies that seek exposure to their brands outside of usual venues such as billboards, television advertisements, and event sponsorships. While the vast majority of the videos retrieved were not uploaded by companies themselves, corporate entities may still have influenced the content and/or placement of these messages. For example, alcohol companies sponsor concerts, parties, and music videos (Siegel, Johnson, et al., 2013).

The most common videos were traditional advertisements. However, these videos were not uploaded by companies themselves. Instead, they were posted by ordinary users and usually featured humor. This finding suggests that social media tends to amplify many of the persuasive messages created and promoted by the alcohol industry. Additionally, because the reposted advertisements represent peer-to-peer communication—as opposed to industry-to-peer communication - they may be particularly influential.

Fully $10 \%$ of the videos featured a single male individual chugging a full bottle of liquor. In each case, the male took careful pains to demonstrate that there was no trick photography by clearly opening the sealed bottle and then immediately drinking the complete bottle in one swallow. In one video with over 650,000 views and over 4000 "like" designations, the host chugged vodka (750 milliliters of $40 \%$ alcohol) in under 30 seconds while in an inpatient rehabilitation unit for alcoholism. Impressionable youth viewing these videos may develop maladaptive attitudes 
regarding factors such as the immediate dangers of binge drinking and the seriousness of rehabilitation.

All videos portrayed the presence of at least one human being. While $95 \%$ of videos featured males, only about half of videos portrayed females, consistent with prior research. One reason for this disparity may be simply because males exhibit more frequent episodic drinking relative to females (Chavez et al., 2011). Another possibility is that alcohol use is generally perceived as more socially acceptable for males (de Visser \& McDonnell, 2012). Because more males are featured, future interventions debunking alcohol-related myths propagated on social media may be useful to target toward males.

We noted a wide variation between negative and positive aspects of alcohol use; while only 2$4 \%$ of videos portrayed aggression, addiction, or injuries, about half of videos portrayed humor. This is a common pattern in media portrayals, because producers often like to emphasize the fun, compelling aspects of alcohol use while downplaying the serious consequences that may be unappealing to users (Jernigan \& Rushman, 2014; Primack et al., 2015; Robinson et al., 1998). Nearly all of the negativity was seen in music videos, some of which tend to portray "gritty" aspects of reality to increase affect. However, overall levels of negativity were still very low; for example, only $2 / 18$ music videos portrayed aggression and only 4/18 portrayed addiction.

We noted that each brand was associated with a distinct set of characteristics. For example, all Patron videos but none of the Bud Light videos portrayed intoxication. This may have been because Patron videos were almost all music videos in which individuals were excessively 
drinking, while Bud Light videos were generally advertisements in which beer was being linked to a fun, friendly, humorous lifestyle. In these situations, portraying intoxication may have been limited by alcohol industry self-regulation codes. For example, the Beer Institute (Beer Institute, 2015) and Distilled Spirits Council of the United States (DISCUS) codes contain social responsibility clauses stating alcohol advertising should not depict excessive or irresponsible drinking (Distilled Spirits Council of the United States, 2011). It should be noted, however, that the alcohol industry is not always faithful to its own guidelines (Center on Alcohol Marketing and Youth, 2004).

In 2012, YouTube added an "Age Gate" to block inappropriate content from underage users (Barry, Johnson, et al., 2015). However, official alcohol companies' YouTube channels are still highly accessible to underage youth (Barry, Johnson, et al., 2015). It is also important to note that in the present study the advertisement videos were not all posted by the alcohol company: some were shared by other users.

Another example of distinct brand associations was that the majority of Bud Light and Coors Light videos featured humor (87\% and 82\%), while brands such as Grey Goose and Jack Daniel's were much less likely to contain humor (14\% and 17\%). Beer brands often used advertisements as a distinctive tactic to connect their product with humor (Jernigan \& Rushman, 2014; Primack et al., 2015) 


\section{Limitations}

We collected our videos at only one point in time. We tried to minimize this limitation by sampling according to both popularity and relevance, but we acknowledge that our results may not be generalizable to other samples of user-generated and posted videos. Though the selected videos reflect brands popular at the time of collection, alcohol preference among underage youth varies over time. Similarly, the selected brands may not be generalizable to brands outside of the scope of this investigation.

Another necessary limitation is that subjectivity is inherent in the coding of variables such as production quality, humor, and attractiveness. While we took steps to minimize this concernsuch as developing a comprehensive codebook with detailed criteria and double-coding — this remains a potential limitation.

Caution should be taken around certain figures provided by YouTube, such as the view count;

for example, this count does not represent unique users and it does not distinguish between U.S. and international users. It was also out of the scope of this study to examine the comments associated with each of the primary videos. While it is appropriate at this early stage of research to begin with the primary videos, it will be exciting for future research to delve into the potentially rich discussion around these primary videos. 


\section{Conclusions}

Despite these limitations, our work suggests that Internet videos depicting alcohol brands have been heavily viewed, generally represent traditional advertisements reposted by users, often include humor, and infrequently depict negative consequences of alcohol use. The stark differences between representation of alcohol brands on YouTube and true known clinical associations with alcohol use may provide an opportunity for educational interventions. Finally, understanding the ways that specific brands are portrayed may help public health practitioners to develop tailored interventions based on brands, which are associated with strong loyalty by consumers in this area. 


\section{ACKNOWLEDGMENTS}

We gratefully acknowledge funding from ABMRF, The Foundation for Alcohol Research. We thank Michelle Woods for editorial assistance. 


\section{REFERENCES}

Anderson, P., de Bruijn, A., Angus, K., Gordon, R., \& Hastings, G. (2008). Impact of alcohol advertising and media exposure on adolescent alcohol use: A systematic review of longitudinal studies. Alcohol and Alcoholism, 44(3), 229-243. https://doi.org/10.1093/alcalc/agn115

Bandura, A. (2001). Social cognitive theory: An agentic perspective. Annual Review of Psychology, 52, 1-26. https://doi.org/10.1146/annurev.psych.52.1.1

Barry, A. E. (2016). Alcohol advertising influences underage brand-specific drinking: Evidence of a linear dose-response relationship. The American Journal of Drug and Alcohol Abuse, 42(1), 1-3. https://doi.org/10.3109/00952990.2015.1104319

Barry, A. E., Bates, A. M., Olusanya, O., Vinal, C. E., Martin, E., Peoples, J. E., ... Montano, J. R. (2015). Alcohol marketing on Twitter and Instagram: Evidence of directly advertising to youth/adolescents. Alcohol and Alcoholism, agv128. https://doi.org/10.1093/alcalc/agv128

Barry, A. E., Johnson, E., Rabre, A., Darville, G., Donovan, K. M., \& Efunbumi, O. (2015). Underage access to online alcohol marketing content: a YouTube case study. Alcohol and Alcoholism (Oxford, Oxfordshire), 50(1), 89-94. https://doi.org/10.1093/alcalc/agu078

Beer Institute. (2015). Advertising and Marketing Code. Washington DC. Retrieved from http://www.beerinstitute.org/assets/uploads/general-upload/2015-Beer-Ad-CodeBrochure.pdf

Beullens, K., \& Van den Bulck, J. (2008). News, music videos and action movie exposure and adolescents' intentions to take risks in traffic. Accident Analysis \& Prevention, 40(1), 349356. https://doi.org/10.1016/j.aap.2007.07.002

Carroll, M. V, Shensa, A., \& Primack, B. A. (2013). A comparison of cigarette- and hookahrelated videos on YouTube. Tobacco Control, 22(5), 319-323. https://doi.org/10.1136/tobaccocontrol-2011-050253

Center on Alcohol Marketing and Youth. (2004). Clicking with kids: Alcohol marketing and youth on the internet. Clicking With Kids: Alcohol Marketing \& Youth On The Internet. Washington DC. Retrieved from http://search.ebscohost.com/login.aspx?direct=true\&db=fgh\&AN=MRB-LAX090530019\&site=ehost-live

Centers for Disease Control and Prevention. (2016). Trends in the prevalence of alcohol use: National YRBS: 1991—2013. Retrieved May 13, 2016, from http://www.cdc.gov/healthyyouth/data/yrbs/pdf/trends/us_alcohol_trend_yrbs.pdf

Chavez, P. R., Nelson, D. E., Naimi, T. S., \& Brewer, R. D. (2011). Impact of a new genderspecific definition for binge drinking on prevalence estimates for women. American Journal of Preventive Medicine, 40(4), 468-471. https://doi.org/10.1016/j.amepre.2010.12.008

Cohen, J. (1960). A coefficient of agreement for nominal scales. Educational and Psychological Measurement, 20(1), 37-46. https://doi.org/10.1177/001316446002000104 
Collins, R. L., Martino, S. C., Kovalchik, S. A., Becker, K. M., Shadel, W. G., \& D’Amico, E. J. (2016). Alcohol advertising exposure among middle school-age youth: An assessment across all media and venues. Journal of Studies on Alcohol and Drugs, 77(3), 384-392. https://doi.org/10.15288/jsad.2016.77.384

Connery, H. S., Albright, B. B., \& Rodolico, J. M. (2014). Adolescent substance use and unplanned pregnancy. Obstetrics and Gynecology Clinics of North America, 41(2), 191203. https://doi.org/10.1016/j.ogc.2014.02.011

Crabtree, B. F., \& Miller, W. L. (1999). Doing qualitative research (2nd ed.). Thousand Oaks, CA: SAGE Publications.

Cranwell, J., Murray, R., Lewis, S., Leonardi-Bee, J., Dockrell, M., \& Britton, J. (2015). Adolescents' exposure to tobacco and alcohol content in YouTube music videos. Addiction, 110(4), 703-711. https://doi.org/10.1111/add.12835

Cranwell, J., Opazo-Breton, M., \& Britton, J. (2016). Adult and adolescent exposure to tobacco and alcohol content in contemporary YouTube music videos in Great Britain: a population estimate. Journal of Epidemiology and Community Health, 70(5), 488-492. https://doi.org/10.1136/jech-2015-206402

de Visser, R. O., \& McDonnell, E. J. (2012). “That”s OK. He's a guy': A mixed-methods study of gender double-standards for alcohol use. Psychology \& Health, 27(5), 618-639. https://doi.org/10.1080/08870446.2011.617444

Distilled Spirits Council of the United States, I. (2011). Code of Responsible Practices. Washington DC. Retrieved from http://www.discus.org/assets/1/7/May_26_2011_DISCUS_Code_Word_Version1.pdf

Engels, R. C. M. E., Hermans, R., van Baaren, R. B., Hollenstein, T., \& Bot, S. M. (2009). Alcohol portrayal on television affects actual drinking behaviour. Alcohol and Alcoholism, 44(3), 244-249. https://doi.org/10.1093/alcalc/agp003

Fischer, P., Greitemeyer, T., Kastenmüller, A., Vogrincic, C., \& Sauer, A. (2011). The effects of risk-glorifying media exposure on risk-positive cognitions, emotions, and behaviors: A meta-analytic review. Psychological Bulletin, 137(3), 367-390. https://doi.org/10.1037/a0022267

Forsyth, S. R., \& Malone, R. E. (2010). "I'll be your cigarette-light me up and get on with it": Examining smoking imagery on YouTube. Nicotine \& Tobacco Research, 12(8), 810-816. https://doi.org/10.1093/ntr/ntq101

Gordon, J. B., Barot, L. R., Fahey, A. L., \& Matthews, M. S. (2001). The Internet as a source of information on breast augmentation. Plastic and Reconstructive Surgery, 107(1), 171-176. https://doi.org/10.1080/14681811.2011.627739

Grenard, J. L., Dent, C. W., \& Stacy, A. W. (2013). Exposure to alcohol advertisements and teenage alcohol-related problems. Pediatrics, 131(2), e369-e379. https://doi.org/10.1542/peds.2012-1480

Gruber, E. L., Thau, H. M., Hill, D. L., Fisher, D. A., \& Grube, J. W. (2005). Alcohol, tobacco and illicit substances in music videos: a content analysis of prevalence and genre. Journal of 
Adolescent Health, 37(1), 81-83. https://doi.org/10.1016/j.jadohealth.2004.02.034

Hanewinkel, R., Sargent, J. D., Hunt, K., Sweeting, H., Engels, R. C. M. E., Scholte, R. H. J., ... Morgenstern, M. (2014). Portrayal of alcohol consumption in movies and drinking initiation in low-risk adolescents. Pediatrics, 133(6), 973-982. https://doi.org/10.1542/peds.20133880

Henriksen, L., Feighery, E. C., Schleicher, N. C., \& Fortmann, S. P. (2008). Receptivity to alcohol marketing predicts initiation of alcohol use. Journal of Adolescent Health, 42(1), 28-35. https://doi.org/10.1016/j.jadohealth.2007.07.005

Hingson, R., Heeren, T., Levenson, S., Jamanka, A., \& Voas, R. (2002). Age of drinking onset, driving after drinking, and involvement in alcohol related motor-vehicle crashes. Accident Analysis \& Prevention, 34(1), 85-92. https://doi.org/10.1016/S0001-4575(01)00002-1

Huang, J., Kornfield, R., \& Emery, S. L. (2016). 100 Million Views of Electronic Cigarette YouTube Videos and Counting: Quantification, Content Evaluation, and Engagement Levels of Videos. Journal of Medical Internet Research, 18(3), e67. https://doi.org/10.2196/jmir.4265

Jernigan, D. H., \& Rushman, A. E. (2014). Measuring youth exposure to alcohol marketing on social networking sites: Challenges and prospects. Journal of Public Health Policy, 35(1), 91-104. https://doi.org/10.1057/jphp.2013.45

Kim, K. H., Paek, H. J., \& Lynn, J. (2010). A content analysis of smoking fetish videos on YouTube: Regulatory implications for tobacco control. Health Communication, 25(2), 97106. https://doi.org/10.1080/10410230903544415

Leighton, H. V, \& Srivastava, J. (1999). First 20 precision among World Wide Web search services (search engines). Journal of the American Society for Information Science, 50(10), 870-881. https://doi.org/10.1002/(SICI)1097-4571(1999)50:10<870::AID-ASI4>3.0.CO;2G

Lenhart, A. (2015). Teens, social media and technology overview 2015: Smartphones facilitate shifts in communication landscape for teens. https://doi.org/10.1016/j.chb.2015.08.026

Madan, A. K., Frantzides, C. T., \& Pesce, C. E. (2003). The quality of information about laparoscopic bariatric surgery on the Internet. Surgical Endoscopy, 17(5), 685-687. https://doi.org/10.1007/s00464-002-8610-7

Marshall, E. J. (2014). Adolescent alcohol use: Risks and consequences. Alcohol and Alcoholism, 49(2), 160-164. https://doi.org/10.1093/alcalc/agt180

Mascheroni, G., \& Ólafsson, K. (2014). Net Children Go Mobile: Risks and opportunities, (May), 1-123. https://doi.org/10.13140/RG.2.1.3590.8561

McCambridge, J., McAlaney, J., \& Rowe, R. (2011). Adult consequences of late adolescent alcohol consumption: A systematic review of cohort studies. PLoS Medicine, 8(2). https://doi.org/10.1371/journal.pmed.1000413

McClure, A. C., Stoolmiller, M., Tanski, S. E., Engels, R. C. M. E., \& Sargent, J. D. (2013). Alcohol marketing receptivity, marketing-specific cognitions, and underage binge drinking. Alcoholism: Clinical and Experimental Research, 37 Suppl 1(January), E404-13. 
https://doi.org/10.1111/j.1530-0277.2012.01932.x

McClure, A. C., Stoolmiller, M., Tanski, S. E., Worth, K. A., \& Sargent, J. D. (2009). Alcoholbranded merchandise and its association with drinking attitudes and outcomes in US adolescents. Archives of Pediatrics \& Adolescent Medicine, 163(3), 211-217. https://doi.org/10.1001/archpediatrics.2008.554

McClure, A. C., Tanski, S. E., Li, Z., Jackson, K., Morgenstern, M., Li, Z., \& Sargent, J. (2016). Internet alcohol marketing and underage alcohol use. Pediatrics, 137(2), 1-8. https://doi.org/10.1542/peds.2015-2149

Moreno, M. A., \& Whitehill, J. M. (2014). Influence of social media on alcohol use in adolescents and young adults. Alcohol Research: Current Reviews, 36(1), 91-100. Retrieved from http://www.pubmedcentral.nih.gov/articlerender.fcgi?artid=4432862\&tool=pmcentrez\&ren dertype $=$ abstract

Oksanen, A., Garcia, D., Sirola, A., Nasi, M., Kaakinen, M., Keipi, T., \& Rasanen, P. (2015). Pro-anorexia and anti-pro-anorexia videos on YouTube: Sentiment analysis of user responses. Journal of Medical Internet Research, 17(11), e256. https://doi.org/10.2196/jmir.5007

Patrick, M. E., \& Schulenberg, J. E. (2013). Prevalence and predictors of adolescent alcohol use and binge drinking in the United States. Alcohol Research : Current Reviews, 35(2), 193200. Retrieved from http://www.pubmedcentral.nih.gov/articlerender.fcgi?artid=3908711\&tool=pmcentrez\&ren dertype $=$ abstract

Primack, B. A., Colditz, J. B., Pang, K. C., \& Jackson, K. M. (2015). Portrayal of alcohol intoxication on YouTube. Alcoholism: Clinical and Experimental Research, 39(3), 496503. https://doi.org/10.1111/acer.12640

Primack, B. A., Dalton, M. A., Carroll, M. V, Agarwal, A. A., \& Fine, M. J. (2008). Content analysis of tobacco, alcohol, and other drugs in popular music. Archives of Pediatrics \& Adolescent Medicine, 162(2), 169-175. https://doi.org/10.1001/archpediatrics.2007.27

Primack, B. A., McClure, A. C., Li, Z., \& Sargent, J. D. (2014). Receptivity to and recall of alcohol brand appearances in U.S. popular music and alcohol-related behaviors. Alcoholism: Clinical and Experimental Research, 38(6), 1737-1744. https://doi.org/10.1111/acer.12408

Primack, B. A., Nuzzo, E., Rice, K. R., \& Sargent, J. D. (2012). Alcohol brand appearances in US popular music. Addiction, 107(3), 557-566. https://doi.org/10.1111/j.13600443.2011.03649.x

Roberts, S. P., Siegel, M. B., DeJong, W., Ross, C. S., Naimi, T., Albers, A., ... Jernigan, D. H. (2015). Brands matter: Major findings from the alcohol brand research among underage drinkers (ABRAND) project. Addiction Research \& Theory, 24(1), 32-39. https://doi.org/10.3109/16066359.2015.1051039

Robinson, T. N., Chen, H. L., \& Killen, J. D. (1998). Television and music video exposure and risk of adolescent alcohol use. Pediatrics, 102(5), E54. Retrieved from 
http://pediatrics.aappublications.org/content/102/5/e54

Ross, C. S., Maple, E., Siegel, M., DeJong, W., Naimi, T. S., Ostroff, J., ... Jernigan, D. H. (2014). The Relationship Between Brand-Specific Alcohol Advertising on Television and Brand-Specific Consumption Among Underage Youth. Alcoholism: Clinical and Experimental Research, 38(8), 2234-2242. https://doi.org/10.1111/acer.12488

Siegel, M., DeJong, W., Naimi, T. S., Fortunato, E. K., Albers, A. B., Heeren, T., ... Jernigan, D. H. (2013). Brand-specific consumption of alcohol among underage youth in the United States. Alcoholism: Clinical and Experimental Research, 37(7), 1195-203. https://doi.org/10.1111/acer.12084

Siegel, M., Johnson, R. M., Tyagi, K., Power, K., Lohsen, M. C., Ayers, A. J., \& Jernigan, D. H. (2013). Alcohol Brand References in U.S. Popular Music, 2009-2011. Substance Use \& Misuse, 48(14), 1475-1484. https://doi.org/10.3109/10826084.2013.793716

Strauss, A., \& Corbin, J. (2007). Basics of qualitative research: Techniques and procedures for developing grounded theory (3rd ed.). Thousand Oaks, California: SAGE Publications.

Tanski, S. E., McClure, A. C., \& Jernigan, D. H. (2011). Alcohol Brand Preference and Binge Drinking Among Adolescents. Archives of Pediatrics \& Adolescent Medicine, 165(7), 675. https://doi.org/10.1001/archpediatrics.2011.113

Tanski, S. E., McClure, A. C., Li, Z., Jackson, K., Morgenstern, M., Li, Z., \& Sargent, J. D. (2015). Cued recall of alcohol advertising on television and underage drinking behavior. Journal of the American Medical Association Pediatrics, 169(3), 264. https://doi.org/10.1001/jamapediatrics.2014.3345

van den Bulck, J., \& Beullens, K. (2005). Television and music video exposure and adolescent alcohol use while going out. Alcohol and Alcoholism, 40(3), 249-253. https://doi.org/10.1093/alcalc/agh139

Volk, R. J., Edwards, D. W., Lewis, R. A., \& Schulenberg, J. (1996). Smoking and preference for brand of cigarette among adolescents. Journal of Substance Abuse, 8(3), 347-359. Retrieved from http://www.ncbi.nlm.nih.gov/pubmed/8934439

World Health Organization. (2016). Youth violence and alcohol fact sheet. Retrieved May 13, 2016, from http://www.who.int/violence_injury_prevention/violence/world_report/factsheets/ft_youth.p df

YouTube. (2016). Statistics. Retrieved June 16, 2016, from https://www.youtube.com/yt/press/statistics.html 
1 TABLE 1. Coding examples selected from the final sample of 137 videos

\begin{tabular}{|c|c|c|}
\hline Code & Definition & Example [YouTube ID] \\
\hline \multicolumn{3}{|l|}{ Video Type } \\
\hline Traditional ads & $\begin{array}{l}\text { A commercial advertising an alcohol brand, } \\
\text { professionally produced, usually } 15 \text { to } 60 \\
\text { seconds long. Its intent is to create positive } \\
\text { associations with the brand. Includes ads } \\
\text { which an amateur third party has dubbed or } \\
\text { otherwise edited a commercial. }\end{array}$ & $\begin{array}{l}\text { A man with a cartoonishly wide mustache demonstrates its utility to his skeptical } \\
\text { friends. He serves Bud Light to two friends, using his facial hair as a bottle } \\
\text { opener. This makes them happy. For the last } 10 \text { seconds of the clip, the visuals } \\
\text { showcase frosty Bud Lights, emphasizing product being sold. The spot is } 61 \\
\text { seconds long, and of a high production quality. [bxwbiyc_fZo] }\end{array}$ \\
\hline \multirow[t]{2}{*}{ Narrative ads } & \multirow{2}{*}{$\begin{array}{l}\text { A short film, interview, or documentary- } \\
\text { style piece, sponsored by a company in } \\
\text { association with a particular beverage } \\
\text { brand. It is possible that a video not } \\
\text { explicitly discuss or show use of the } \\
\text { product itself, it is enough that it be } \\
\text { produced by an alcoholic beverage } \\
\text { company. }\end{array}$} & $\begin{array}{l}\text { Black and white shots of rap artist Nas speaking to the camera about the concert } \\
\text { which launched his partnership with Hennessey are interspersed with clips from } \\
\text { the event and shots of Hennessey. Only the cognac bottle is in color. [R1v- } \\
\text { nj9XW0o] }\end{array}$ \\
\hline & & $\begin{array}{l}\text { The Coors Light logo opens this video, which continues with the headlines "One } \\
\text { filmmaker \& one rider. } 3 \text { days to create the best film." It appears to be a finalist } \\
\text { or winner in a competition sponsored by the beer manufacturer. The short film } \\
\text { continues with a strange, wordless story of a man in a clown mask performing } \\
\text { tricks on skis. No alcoholic products are featured after the opening sequence. [9t- } \\
\text { u2XQqh8] }\end{array}$ \\
\hline Guide & $\begin{array}{l}\text { One or more hosts showcase an alcoholic } \\
\text { beverage and discuss its consumption. } \\
\text { They may weigh its merits and downsides, } \\
\text { or provide recipes or serving suggestions. }\end{array}$ & $\begin{array}{l}\text { Standing alone in a kitchen, a man shows that he has purchased luxury brand } \\
\text { Grey Goose and bargain Costco store brand vodka. He explains that he wants to } \\
\text { see if there's a discernible difference between the two, and help the viewer make } \\
\text { purchase decisions. He sips both and discusses his preference. [aY_pmYUIZ-I] }\end{array}$ \\
\hline Music & $\begin{array}{l}\text { Music plays as the primary audio of the } \\
\text { video. The focus of the video is on the } \\
\text { music, with the visuals intended to } \\
\text { complement and accompany the audio } \\
\text { track. This designation includes, but is not } \\
\text { limited to, commercial music videos and } \\
\text { homemade lyrics videos. }\end{array}$ & $\begin{array}{l}\text { A band bounces around a dark stage with neon flashing lights in the background, } \\
\text { singing and playing their original song "Duck Duck Grey Goose." This upload is } \\
\text { its official music video, put online by their label. [I-M46G6b0Xs] }\end{array}$ \\
\hline Chugging & $\begin{array}{l}\text { Feature a visual of a person drinking or } \\
\text { attempting to drink an entire alcoholic } \\
\text { beverage at a rapid speed. The size of the } \\
\text { product should be at least } 375 \mathrm{ml} / 12 \mathrm{oz} \text {. }\end{array}$ & $\begin{array}{l}\text { Sitting in his home, a middle aged man shows the camera a full bottle of } \\
\text { Smirnoff raspberry. After laughing about how disgusting his actions will be, he } \\
\text { proceeds to drink the entire } 750 \mathrm{ml} \text { bottle of } 80 \text { proof liquor without pausing. } \\
\text { [fjq-hnT6UlI] }\end{array}$ \\
\hline Other & The video features a brand of alcohol, but & This upload by the Associated Press relates a news story about a man who \\
\hline
\end{tabular}




\begin{tabular}{|c|c|c|}
\hline & $\begin{array}{l}\text { does not fulfill the requirements of the five } \\
\text { previous categories. }\end{array}$ & $\begin{array}{l}\text { mistakenly gave his child a Mike's Hard Lemonade, unaware of its alcohol } \\
\text { content. [_4DGidVLmMs] }\end{array}$ \\
\hline \multicolumn{3}{|c|}{ Production Quality } \\
\hline Poor & $\begin{array}{l}\text { Filmed in a convenient location with little } \\
\text { or no attention to lighting, camera angles, } \\
\text { background, audio quality, or editing. }\end{array}$ & $\begin{array}{l}\text { The audio track features the song "Hennessey And Buddah" by rap artist Snoop } \\
\text { Dogg. Throughout the five minute song, the visual never changes from a slightly } \\
\text { distorted still picture of the album cover. This upload is unaffiliated with the } \\
\text { artist or his company. [cqveNUOmebg] }\end{array}$ \\
\hline Moderate & $\begin{array}{l}\text { Some attention to lighting, camera angles, } \\
\text { background, audio quality, and some } \\
\text { editing cuts }\end{array}$ & $\begin{array}{l}\text { Sitting at a table, a man states that he is a "super taster" for chow.com. The man } \\
\text { explains that he will be trying Mike's Hard Chocolate Cherry beverage. He } \\
\text { anticipates that he will not like the drink and portrays the flavor negatively. After } \\
\text { tasting the beverage, the man is disgusted and rates the drink as the third worst } \\
\text { item he has ever tried for chow.com. The visuals focus on the man sitting at his } \\
\text { table with occasional close-up images of the product. [pGHkZXRv43k] }\end{array}$ \\
\hline Professional & $\begin{array}{l}\text { Good lighting, several camera angles, } \\
\text { compelling and consciously chosen } \\
\text { backgrounds, good audio quality and/or } \\
\text { editing }\end{array}$ & $\begin{array}{l}\text { Hip hop artist Ice Cube sings in a recording studio. A Coors Light bottle takes } \\
\text { over, and throws a party. Annoyed, Ice Cube screws the cap back on the bottle. } \\
\text { This shows the viewer the new feature that Coors wishes to exemplify, a lid } \\
\text { which can be put back on. During the last third of the } 30 \text { second video, the } \\
\text { voiceover and visuals focus on the product. [LF13-8mrsvQ] }\end{array}$ \\
\hline \multicolumn{3}{|c|}{ Negative Associations with Alcohol Use } \\
\hline Aggression & $\begin{array}{l}\text { Aggressive behavior noted in a "serious" } \\
\text { context }\end{array}$ & $\begin{array}{l}\text { Blurry footage shot at a party event sponsored by Ciroc. The rapper Diddy can be } \\
\text { heard shouting profanity at one of the guests for drinking competitor product } \\
\text { Grey Goose. He repeatedly yells phrases including "Put that shit down!" and } \\
\text { "Get the fuck out of here!" The guest responds with similar language and tone. } \\
\text { [V5FDh5v9whY] }\end{array}$ \\
\hline Addiction & $\begin{array}{l}\text { Specific reference to being a "drunk," } \\
\text { being an "addict," depiction of physical } \\
\text { tolerance or withdrawal, or similar } \\
\text { language or representation. }\end{array}$ & $\begin{array}{l}\text { Country music singer Chase Rice's picture shows throughout the video, with the } \\
\text { audio featuring his song "Jack Daniel's and Jesus." Lyrics include "It's my fault } \\
\text { that I ain't called my momma in a month of Sundays. She'll smell the whiskey } \\
\text { through that phone. I can't stand to hear her heartbreak." [sCNQPPcY3us] }\end{array}$ \\
\hline Intoxication & $\begin{array}{l}\text { Apparent slurring of speech, awkwardness } \\
\text { of movement, reduction of social } \\
\text { inhibitions, or other signs of acute } \\
\text { intoxication }\end{array}$ & $\begin{array}{l}\text { A promotional video from the Smirnoff Ice Summer Tour. This was filmed } \\
\text { during a tour stop in Venezuela. People dance and party with cups in their hands. } \\
\text { The dancing becomes wilder as the video continues. The escalating inebriation is } \\
\text { additionally evident as people yell and cheer, drop drinks, and splash each other } \\
\text { in pools. [mV9vL4hozoU] }\end{array}$ \\
\hline Injury & $\begin{array}{l}\text { An injury that might require a hospital or } \\
\text { physician visit }\end{array}$ & $\begin{array}{l}\text { A woman believes her date has a stripper pole in his living room. She begins to } \\
\text { dance around it. In reality, it is a fireman's pole which allows upstairs neighbors } \\
\text { to quickly descend in search of Bud Light. One such neighbor lands directly on }\end{array}$ \\
\hline
\end{tabular}




\begin{tabular}{|c|c|c|}
\hline & & $\begin{array}{l}\text { her head, knocking her to the ground. At the end of the commercial a second } \\
\text { neighbor lands on the first, repeating the injurious physical comedy. } \\
\text { [PSGySgH411A] }\end{array}$ \\
\hline & & $\begin{array}{l}\text { This beer advertisement features a preppy man showing off his pure-bred dog. } \\
\text { He directs the pet to retrieve a Bud Light from a cooler. In response, an average } \\
\text { man commands his mutt to do the same. The dog achieves by biting the preppy } \\
\text { man's crotch, causing him to throw his drink to the mutt's owner. } \\
\text { [NFg3HBMJyV4] }\end{array}$ \\
\hline \multirow[t]{2}{*}{ Vehicle Use } & \multirow{2}{*}{$\begin{array}{l}\text { A member of the focal group comes in } \\
\text { physical contact with a motor vehicle }\end{array}$} & $\begin{array}{l}\text { The lyrics to the featured song, "I'm on Patron," mention vehicles multiple times. } \\
\text { The chorus repeats "I'm gone, so gone, so throwed, can I get a ride home," } \\
\text { indicating that the narrator is too inebriated to operate an automobile. The lyric } \\
\text { "If I get pulled over TV Jonny pay my bond," suggests he may decide to drive } \\
\text { regardless. [1jX2XeL4lYU] }\end{array}$ \\
\hline & & $\begin{array}{l}\text { In this 30-second Smirnoff spot, the model Amber Rose visits two parties. Their } \\
\text { theming suggests first Smirnoff Fluffed, then Smirnoff Whipped. To facilitate } \\
\text { transportation between the glamorous events, she is chauffeured in a retro car. } \\
\text { The happy, laughing protagonist rides accompanied by two more glamorous } \\
\text { persons. [kIgaNxbR6zQ] }\end{array}$ \\
\hline \multicolumn{3}{|c|}{ Positive Associations with Alcohol Use } \\
\hline Humor & $\begin{array}{l}\text { Containing content likely humorous to the } \\
\text { intended audience* }\end{array}$ & $\begin{array}{l}\text { A man asks a squirrel to guard his Bud Light. As soon as he walks away, his } \\
\text { friend tries to drink the beverage. The squirrel jumps on the thief's face and } \\
\text { punches him with tiny fists. The short ad contains both physical and verbal gags. } \\
\text { [kiTarkl31Gw] }\end{array}$ \\
\hline Attractiveness & $\begin{array}{l}\text { Containing people likely to be physically } \\
\text { attractive to the intended audience* }\end{array}$ & $\begin{array}{l}\text { Musical artist Trina sings and dances in her music video. She is slim with a curvy } \\
\text { figure, high cheek bones, and full lips. She wears makeup and is dressed to } \\
\text { accentuate her attractive physical qualities. [OTMlvJLAMCk] }\end{array}$ \\
\hline
\end{tabular}


3 TABLE 2. Characteristics of 137 YouTube videos according to brand

\begin{tabular}{|c|c|c|c|c|c|c|c|c|c|}
\hline & $\begin{array}{l}\text { Bud Light } \\
n=23\end{array}$ & $\begin{array}{c}\text { Coors Light } \\
n=28\end{array}$ & $\begin{array}{c}\text { Grey Goose } \\
n=22\end{array}$ & $\begin{array}{c}\text { Hennessy } \\
\mathrm{n}=13\end{array}$ & $\begin{array}{c}\text { Jack } \\
\text { Daniel's } \\
\mathrm{n}=18\end{array}$ & $\begin{array}{c}\text { Mike's Hard } \\
n=20\end{array}$ & $\begin{array}{c}\text { Patron } \\
n=4\end{array}$ & $\begin{array}{c}\text { Smirnoff } \\
n=9\end{array}$ & $p^{*}$ \\
\hline \multicolumn{10}{|l|}{ General } \\
\hline \multicolumn{10}{|l|}{ Category } \\
\hline Traditional ads & 19 [83] & 18 [64] & $4[18]$ & $0[0]$ & $4[22]$ & 7 [35] & $0[0]$ & $3[33]$ & \multirow{6}{*}{$<.001$} \\
\hline Narrative ads & $0[0]$ & 7 [25] & $1[5]$ & $5[38]$ & $1[6]$ & $0[0]$ & $0[0]$ & $2[22]$ & \\
\hline Guide & $2[9]$ & $1[4]$ & $6[27]$ & $2[15]$ & $5[28]$ & $10[50]$ & $0[0]$ & $1[11]$ & \\
\hline Music & $1[4]$ & $0[0]$ & $5[23]$ & $4[31]$ & 3 [17] & $2[10]$ & $2[50]$ & $1[11]$ & \\
\hline Chugging & $0[0]$ & $0[0]$ & 5 [23] & $4[31]$ & $3[17]$ & $2[10]$ & $2[50]$ & $2[22]$ & \\
\hline Other & $1[4]$ & $2[7]$ & $1[5]$ & $1[8]$ & $1[6]$ & $1[5]$ & $0[0]$ & $0[0]$ & \\
\hline \multicolumn{10}{|l|}{ Production } \\
\hline Poor & $2[9]$ & $1[4]$ & 10 [45] & $4[31]$ & $8[44]$ & $6[30]$ & $2[50]$ & 3 [33] & \multirow{3}{*}{.01} \\
\hline Moderate & $1[4]$ & $6[21]$ & $1[4]$ & $2[15]$ & $2[11]$ & $5[25]$ & $0[0]$ & $0[0]$ & \\
\hline Professional & 20 [87] & $21[75]$ & $11[50]$ & 7 [54] & $8[44]$ & $9[45]$ & $2[50]$ & $6[67]$ & \\
\hline \multicolumn{10}{|l|}{ Demographic } \\
\hline Male & 22 [96] & 28 [100] & 21 [95] & 13 [100] & 16 [89] & 18 [90] & $4[100]$ & 8 [89] & .60 \\
\hline Female & 13 [57] & $9[32]$ & 9 [41] & $4[31]$ & 4 [22] & $8[40]$ & 3 [75] & $5[56]$ & .25 \\
\hline White & 22 [96] & 22 [79] & $12[55]$ & $6[46]$ & 15 [83] & 18 [90] & $3[75]$ & 8 [89] & .004 \\
\hline Black & $8[35]$ & $17[61]$ & $9[41]$ & $8[62]$ & $1[6]$ & $0[0]$ & $2[50]$ & $1[11]$ & $<.001$ \\
\hline Other race & $3[13]$ & $2[7]$ & $4[18]$ & $1[8]$ & $1[6]$ & $3[15]$ & $1[25]$ & $1[11]$ & .86 \\
\hline Mixed group & $10[43]$ & $13[46]$ & $3[14]$ & $2[15]$ & $1[6]$ & $1[5]$ & $2[50]$ & $1[11]$ & $<.001$ \\
\hline \multicolumn{10}{|c|}{ Negative Association with Alcohol Use } \\
\hline Aggression & $0[0]$ & $0[0]$ & $3[14]$ & $0[0]$ & $0[0]$ & $0[0]$ & $0[0]$ & $0[0]$ & .03 \\
\hline Addiction & $0[0]$ & $0[0]$ & $1[5]$ & $0[0]$ & $3[17]$ & $0[0]$ & $0[0]$ & $0[0]$ & .03 \\
\hline Intoxication & $0[0]$ & $2[7]$ & $8[36]$ & $5[38]$ & $2[11]$ & $2[10]$ & $4[100]$ & $3[33]$ & $<.001$ \\
\hline Injury & $6[26]$ & $0[0]$ & $0[0]$ & $0[0]$ & $0[0]$ & $0[0]$ & $0[0]$ & $0[0]$ & $<.001$ \\
\hline Vehicle use & $0[0]$ & $1[4]$ & $1[5]$ & $2[15]$ & $0[0]$ & $2[10]$ & $1[25]$ & $4[44]$ & .001 \\
\hline \multicolumn{10}{|c|}{ Positive Association with Alcohol Use } \\
\hline Humor & $20[87]$ & $23[82]$ & $3[14]$ & $3[23]$ & $3[17]$ & $8[40]$ & $1[25]$ & $4[44]$ & $<.001$ \\
\hline
\end{tabular}



Attractiveness
10 [43]
6 [21]
6 [27]
7 [54]
3 [17]
4 [20]
$2[50]$
4 [44]

4 Notes: Cell contents for each video category column are n [column percentage]. P-values were determined using chi-square tests.

5 Bold values indicate statistical significance at $p<.05$. 
7 TABLE 3. Characteristics of 137 YouTube videos according to video type

\begin{tabular}{|c|c|c|c|c|c|c|c|}
\hline & $\begin{array}{c}\text { Traditional } \\
\text { Advertisement } \\
\mathrm{n}=55\end{array}$ & $\begin{array}{c}\text { Narrative } \\
\text { Advertisement } \\
\mathrm{n}=16\end{array}$ & $\begin{array}{l}\text { Guide } \\
\mathrm{n}=27\end{array}$ & $\begin{array}{l}\text { Music } \\
\mathrm{n}=18\end{array}$ & $\begin{array}{c}\text { Chugging } \\
n=14\end{array}$ & $\begin{array}{c}\text { Other } \\
\mathrm{n}=7\end{array}$ & $p^{*}$ \\
\hline \multicolumn{8}{|l|}{ Characteristics } \\
\hline \multicolumn{8}{|c|}{ Production Quality } \\
\hline Poor & $0[0]$ & $0[0]$ & 13 [48] & $8[44]$ & 14 [100] & $1[14]$ & \\
\hline Moderate & $6[11]$ & $0[0]$ & $7[26]$ & $1[6]$ & $0[0]$ & 3 [49] & $<.001$ \\
\hline Professional & 49 [89] & 16 [100] & 7 [26] & $9[50]$ & $0[0]$ & $3[43]$ & \\
\hline \multicolumn{8}{|l|}{ Demographic } \\
\hline Male & 53 [96] & 16 [100] & 26 [96] & 14 [78] & $14[100]$ & 7 [100] & .02 \\
\hline Female & 29 [53] & $6[38]$ & 3 [11] & $11[61]$ & 3 [21] & $3[43]$ & .002 \\
\hline White & 47 [85] & 11 [69] & 24 [89] & $9[50]$ & $9[64]$ & $6[86]$ & .02 \\
\hline Black & 25 [45] & $5[31]$ & $1[4]$ & $10[56]$ & $2[14]$ & 3 [43] & .001 \\
\hline Other ethnicity & 5 [9] & 3 [19] & $3[11]$ & $2[11]$ & $3[21]$ & $0[0]$ & .64 \\
\hline Mixed group & $22[40]$ & $3[19]$ & $1[4]$ & $5[28]$ & $0[0]$ & $2[29]$ & .002 \\
\hline \multicolumn{8}{|c|}{ Negative Association with Alcohol Use } \\
\hline Aggression & $0[0]$ & $0[0]$ & $0[0]$ & $2[11]$ & $0[0]$ & $1[14]$ & .02 \\
\hline Addiction & $0[0]$ & $0[0]$ & $0[0]$ & $4[22]$ & $0[0]$ & $0[0]$ & $<.001$ \\
\hline Intoxication & $0[0]$ & $2[13]$ & $0[0]$ & 12 [67] & 11 [79] & $1[14]$ & $<.001$ \\
\hline Injury & $6[11]$ & $0[0]$ & $0[0]$ & $0[0]$ & $0[0]$ & $0[0]$ & .10 \\
\hline Vehicle use & $2[4]$ & $2[13]$ & $0[0]$ & $7[39]$ & $0[0]$ & $0[0]$ & $<.001$ \\
\hline \multicolumn{8}{|c|}{ Positive Association with Alcohol Use } \\
\hline Humor & 43 [78] & $2[13]$ & $9[33]$ & $2[11]$ & $5[36]$ & $4[57]$ & $<.001$ \\
\hline Attractiveness & $20[36]$ & 10 [63] & $3[11]$ & 8 [44] & $0[0]$ & $1[14]$ & .001 \\
\hline
\end{tabular}

8 Notes: Cell contents for each video category column are $\mathrm{n}$ [column percentage]. P-values were determined using chi-square tests. Bold values

9 indicate statistical significance at $\mathrm{p}<.05$ which was defined using a two-tailed alpha of 0.05 . 